\title{
A sala de aula como território para um processo de ensino e de aprendizagem situado: Territorialidade e letramento geográfico
}

\section{The classroom as a territory for a situated teaching and learning process: Territoriality and Geographical Literacy}

\section{El aula como territorio para un proceso de enseñanza y aprendizaje situado: territorialidad y alfabetización geográfica}

\footnotetext{
${ }^{1}$ Doutorando em Educação - Universidade Federal de Minas Gerais-UFMG- Brasil, Mestre em Ciências Ambientais - Universidade Estadual do Sudoeste da Bahia; Professor da Faculdade de Educação da Universidade do Estado de Minas Gerais- UEMG, Brasil, daniel.alves@uemg.br.
}

\section{Resumo}

Este artigo tem como objetivo promover um diálogo crítico-reflexivo entre letramento, território e ensino formal de geografia. Para tanto, problematiza a concepção contra-hegemônica de letramento vinculada ao conceito geográfico da categoria território. Como percurso metodológico, o artigo adota uma abordagem qualitativa, valendo-se dos procedimentos pesquisa documental e bibliográfica. Dentre as análises realizadas, a concepção da sala de aula como um território situado e conectado com os diversos contextos de variação social, revela-se como imprescindível para a promoção do dialético processo de socioconstrução do saber geográfico. Todavia, o estabelecimento de um processo de ensino e de aprendizagem efetivamente dialógico esbarra na tendência de padronização das práticas pedagógicas, especialmente aquelas relacionadas à ciência geográfica.

Palavras-chave: Ensino de geografia. Letramento. Território.

\begin{abstract}
This article aims to promote a critical-reflective dialogue between literacy, territory and formal geography education. To this end, it problematizes the counter-hegemonic conception of literacy linked to the geographical concept of the territory category. As a methodological approach, the article adopts a qualitative approach, using the documental and bibliographical research procedures. Among the analyzes carried out, the conception of the classroom as a territory situated and connected with the various contexts of social variation, proves to be essential for the promotion of the dialectical process of socio-construction of geographical knowledge. However, the establishment of an effectively dialogical teaching and learning process bumps into the tendency to standardize pedagogical practices, especially those related to geographical science.
\end{abstract}

Keywords: Geography teaching. Literacy Territory. 


\section{Resumen}

Este artículo tiene como objetivo promover un diálogo crítico-reflexivo entre alfabetización, territorio y educación formal en geografía. Con este fin, problematiza la concepción contrahegemónica de la alfabetización vinculada al concepto geográfico de la categoría de territorio. Como enfoque metodológico, el artículo adopta un enfoque cualitativo, utilizando los procedimientos de investigación documental y bibliográfica. Entre los análisis realizados, la concepción del aula como un territorio situado y conectado con los diversos contextos de variación social, se revela como indispensable para la promoción del proceso dialéctico de socioconstrucción del conocimiento geográfico. Sin embargo, el establecimiento de un proceso de enseñanza y aprendizaje efectivamente dialógico choca con la tendencia a estandarizar las prácticas pedagógicas, especialmente las relacionadas con la ciencia geográfica.

Palabras clave: Enseñanza de geografía. Alfabetización Territorio.

\section{Introdução}

Este artigo ancora-se na perspectiva do letramento como prática social situada que, como nos ensinou Street (1984), é marcada por relações de poder e ideologia, as quais, ao influenciarem os usos sociais das práticas de leitura e escrita, interferem no processo de ensino e de aprendizagem dos diversos gêneros acadêmicos adotados pelos diferentes saberes, dentre eles, aqueles relacionados à ciência geográfica que, muitas vezes, não têm a linguagem escrita como principal modo de leitura.

Conforme Freire (1989, p.7) "a leitura do mundo precede a leitura da palavra", ou seja, para o sujeito aprender a ler as palavras ele precisa também aprender a ler o mundo.

Isto porque a leitura da palavra é sempre precedida da leitura do mundo. E aprender a ler, a escrever, alfabetizar-se é, antes de mais nada, aprender a ler o mundo, compreender o seu contexto, não numa manipulação mecânica de palavras, mas numa relação dinâmica que vincula linguagem e realidade. Adernais, a aprendizagem da leitura e a alfabetização são atos de educação e educação é um ato fundamentalmente político. Paulo Freire reafirma a necessidade de que educadores e educandos se posicionem criticamente ao vivenciarem a educação, superando as posturas ingênuas ou "astutas", 
negando de vez a pretensa neutralidade da educação (FREIRE, 1989, p. 7).

Por essa acepção, entendemos, no âmbito da educação formal, que a sala de aula, onde se desenvolvem as práticas de leitura e escrita pelas quais os conhecimentos inerentes aos variados campos de saberes são sócioconstruídos, constitui-se como um território para o processo de ensino e de aprendizagem do aluno, um sujeito ativo desse processo dotado de capacidade para transformar a realidade social por ele criticamente interpretada.

A categoria território, por sua vez, é aqui entendida à luz de Raffestin (1987; 1993), segundo o qual, o território não se traduz meramente num espaço físico objetivo qualquer, pelo contrário, nele se desvelam as relações intersubjetivas que se materializam na (re)construção social do conhecimento. Essas relações são prenhes de poder, ideologias, embates, conflitos, rupturas, continuidades que se vinculam às dimensões sociais, políticas, históricas, econômicas, culturais, ambientais e tecnológicas, as quais estão presentes no processo de ensino e de aprendizagem, ou seja, são inerentes ao processo de escolarização.

Entender o letramento como prática social situada e, ao mesmo tempo, a sala de aula como território do processo de ensino e de aprendizagem, significa reforçar a tese de que a finalidade desse processo não se restringe ao mero treinamento generalista de habilidades técnicas ou, conforme Soares e Frade et. al. (2014), não se limita ao sentido restrito do domínio do sistema alfabético-ortográfico e da aprendizagem do ler e do escrever. No território da sala de aula, a territorialidade humana acontece, se desenvolve e ganha complexidade, visto que, “[...] não é apenas constituída por relações com os territórios, mas também através de relações concretas com áreas abstratas, tais como línguas, religiões, tecnologias" (RAFFESTIN, 1987, p.267). Parafraseando Raffestin (1993), os sujeitos do processo de ensino e de aprendizagem ao se apropriarem do espaço da sala de aula, territorializam concreta e abstratamente esse espaço.

Nesse sentido, este artigo que tem como objetivo promover um diálogo críticoreflexivo entre letramento, território e ensino formal de Geografia ${ }^{2}$, problematiza a concepção contra-hegemônica de letramento inspirada em Street (1984), vinculando-a ao conceito geográfico da categoria território defendido por Raffestin $(1987 ; 1993)$.

\footnotetext{
2 "Antes tínhamos uma geografia com forma, mas sem conteúdo, e passamos a uma geografia com conteúdo, mas sem forma” (MOREIRA, 2007, p. 118).
} 
Dentre os motivos que levaram a este estudo, destacamos aqueles que se apresentaram como elementos por demais instigantes para um estudo relacional entre a concepção moderna que as práticas de letramento assumiram na academia e a (re)significação dos usos dos recursos inerentes ao ensino da Geografia, no contexto de uma sociedade que se concebe, segundo Corrêa \& Jorge (2009), como grafocentrica e tecnológica:

Primeiro, os novos estudos sobre letramento que o situam num contexto de ideologia e poder e, portanto, ultrapassam a visão de mera habilidade neutra, tecnicista e generalista, diante de um modelo de sociedade atual que se caracteriza geograficamente, conforme Santos (1998), como "técnico-científica-informacional";

E os resultados divulgados, no ano de 2016, pelo Instituto Nacional de Estudos e Pesquisas Educacionais Anísio Teixeira (INEP), segundo os quais, o uso do quadro e giz ainda ocupa papel central no processo de letramento geográfico em detrimento de recursos próprios do ensino da Geografia, a exemplo da leitura de mapas ${ }^{3}$.

Como percurso metodológico, o artigo adota uma abordagem qualitativa (BOGDAN; BIKLEN, 1994), que possibilitará a compreensão da tríade Letramento Território - Ensino de Geografia, valendo-se dos seguintes procedimentos:

Pesquisa bibliográfica por meio de levantamentos, consultas e leituras de artigos, dissertações, teses, capítulos, livros e outras fontes que tratam da temática em estudo, o que subsidiará as reflexões posteriores.

Pesquisa documental a partir da análise às Diretrizes Curriculares Nacionais para o Ensino de Geografia (DCNs), buscando-se observar, do ponto de vista do conteúdo, o que oficialmente diz esse documento normativo sobre as práticas de letramento relacionadas ao ensino dessa ciência.

$\mathrm{O}$ artigo se estrutura em três seções, pelo que, a primeira refere-se a esta introdução. Sequencialmente, apresentamos o referencial teórico que se ancora em estudiosos que compartilham de uma concepção moderna de letramento sensível aos contextos sociais de variação, portanto, numa perspectiva interacionista e sóciodiscursiva de linguagem, que possibilitou uma mudança no paradigma dos usos e significados das práticas de letramento, alargando o seu conceito para além do domínio de técnicas neutras de leitura e escrita desconexas das variações contextuais. Nessa seção, também, realizamos a análise crítica das DCNs, um dos instrumentos oficiais que

\footnotetext{
${ }^{3}$ Os mapas têm como finalidade: “[...] comunicar o conhecimento de poucos para muitos, por conseguinte ele deve ser elaborado de forma a realmente comunicar" (LOCH, 2006, p. 27).
} 
tratam da formação do professor de Geografia e do ensino dessa ciência, procurando relacionar com as ideias de autores que pensam a educação numa perspectiva dialógica e contra-hegemônica como estratégia de aproximação conceitual entre letramento e território, que é o que pretendemos com este artigo.

Concluímos com as considerações finais entendendo que a sala de aula constituise como um território, já que o processo de ensino e de aprendizagem que ali se (re)constrói por meio de práticas pedagógicas situadas, decorre de interações entre sujeitos, as quais são marcadas por relações ideológicas e de poder num dado contexto, por meio de um processo dialético de socioconstrução do saber. Todavia, o estabelecimento de um processo de ensino e de aprendizagem efetivamente dialógico esbarra na tendência de padronização das práticas de letramento geográfico hegemonicamente adotado no ensino formal da ciência geográfica.

\section{A sala de aula como território de aprendizagem num contexto sociocultural e tecnológico}

De acordo com estudos que se dedicam à problematização das práticas de letramento em cursos do ensino superior, dentre os quais os intitulados "A experiência de ensinar Leitura e Produção de Textos nas modalidades presencial e a distância" (CORRÊA; JORGE, 2009), "A escrita nas práticas de letramento acadêmico" (MARINHO, 2010) e "Práticas de letramento acadêmico em um curso de Geografia" (NEVES-JUNIOR, 2012), as práticas de letramento que se desenvolvem no cotidiano das aulas, sejam elas presenciais ou a distância, constituem elementos importantes para a efetividade do processo de ensino e de aprendizagem dos diferentes saberes que, por suas heterogeneidades, demandam “[...] letramentos acadêmicos no plural, baseados numa perspectiva sensível aos contextos de variação" (STREET, 2012, p. 91).

Essa nova visão sobre o letramento enquanto prática social que se molda à dinâmica contextual e, portanto, distancia-se da noção de treinamento generalista de habilidades técnicas, e aproxima-se da noção de "estado ou condição que adquire um grupo social ou um indivíduo como consequência de ter-se apropriado da escrita e de suas práticas” (SOARES, 1999, p.39). A esse respeito, Corrêa \& Jorge (2009) contextualizam que: 
Nos últimos anos, as pesquisas do linguista suíço Jean-Paul Bronkart, difundidas no Brasil principalmente pelo livro Atividades de linguagem, textos e discursos: por um interacionismo sócio-discursivo (1999), também influenciaram sobremaneira pesquisadores e professores comprometidos com objetos e metodologias das aulas de linguagem. $\mathrm{O}$ interacionismo sóciodiscursivo embasa-se principalmente no pensamento de Michel Foucault, com suas teorizações sobre as formações discursivas, e Mikhail Bakhtin, com seus postulados sobre a interação verbal e as condições de produção do discurso [...] (JORGE; CORRÊA, 2009, p. 3).

Assim, pode-se inferir que essas bases filosóficas, ao inspirarem linguistas modernos, inseriram no cenário acadêmico novas discussões que alargaram o conceito de letramento para além do domínio de técnicas neutras de letramento desconexas das variações contextuais que são provocadas pelas interações sociais. O letramento, a partir da difusão dos novos conhecimentos propiciada pelo nascimento da linguística moderna, investe-se de uma nova concepção:

[...] Um conjunto de habilidades de leitura e escrita adquiridas a partir de um contexto de formação profissional superior e vinculadas aos diversos valores atribuídos às práticas de leitura e escrita pelos sujeitos envolvidos (MACEDO; NEVES-JÚNIOR, 2016, p. 69).

A ampliação conceitual do letramento como uma prática dialógica, já que compreendido a partir da difusão dos novos conhecimentos da linguística como uma forma de interação social, aproxima-se do conceito geográfico atribuído à categoria território, visto que, para Costa (2008, p.181), o território é “[...] dinâmico e não estático, uma vez que pontua o processo de territorialização", que implica referentes identitários (o tempo, o espaço, a cultura e os sistemas de crença) sem os quais, segundo Clavall (1999), não se poderia defini-lo. Por essa acepção geográfica, nota-se uma aproximação conceitual de território com a concepção linguística acerca dos novos estudos sobre letramento.

Nessa perspectiva, letramento e território, enquanto construções socioculturais, se complementam em processos de ensino e de aprendizagem pautados em propostas pedagógicas dialógicas. Para Clavall (1999):

Há crises identitárias que provocam frequentemente uma modificação da relação com o espaço: as transformações da realidade espacial correm o risco de provocar, ao contrário, um questionamento das 
ALVES, D. A.

construções identitárias; elas devem ser reformuladas ou reconstruídas sobre novas bases (CLAVALL, 1999, p.16).

Essa aproximação conceitual (re)significa os espaços formais de ensino e de aprendizagem, dentre eles, o da sala de aula que, enquanto território para o letramento, deixa de ser um espaço pedagógico em que práticas de leitura e escrita são passivamente transmitidas por técnicas neutras e generalistas. Entretanto Macedo e Neves-Júnior (2016), advertem que os resultados de uma pesquisa sobre letramento em cursos de licenciatura em Geografia

Indicam que o uso do quadro a giz durante as aulas expositivas ocupou um papel central. A leitura de mapas mostrou-se uma atividade periférica durante o curso, na medida em que estes, retirados de livros didáticos, eram apenas mencionados pelo professor como recurso ilustrativo dos conteúdos, e não como conteúdo a ser ensinado (MACEDO; NEVES-JUNIOR, 2016, p. 68).

Na contramão desses resultados, novos estudos sobre letramento apontam para a potencialidade que outros modos desempenham no processo de ensino e aprendizagem e que, muitas vezes, são ignorados pela predominância da linguagem verbal. Autores como Kress (2003, p. 48), ao definirem que texto, por exemplo, é "qualquer instância comunicativa em qualquer modo semiótico ou em qualquer combinação de modos", contribuem para a compreensão de que gêneros não verbais e/ou multimodais podem ser melhor aproveitados, visto que, conforme Rojo (2013): “múltiplos gêneros linguísticos como mapa, texto, imagem e som se entrecruzam". O ato de ler por meio desse gêneros híbrido-linguísticos

[...] é variável, não absoluto. Em sua definição moderna mais ampla, a leitura é como se sabe, 'a capacidade de extrair sentido de símbolos escritos ou impressos'. O leitor 'emprega os símbolos para orientar a recuperação de informações de sua memória e, em seguida, cria, com essas informações, uma interpretação plausível da mensagem do escritor'. Entretanto, nem sempre a leitura foi definida desse modo. No início, ela consistia na mera capacidade de obtenção de informações visuais com base em algum sistema codificado, bem como na concepção de seu significado. Mais tarde, passou a significar, quase de modo exclusivo, a compreensão de um texto contínuo com sinais escritos sobre uma superfície gravada. Mais recentemente, incluiu também a extração de informações codificadas de uma tela eletrônica. E a definição de leitura continuará, por certo, a se expandir no futuro porque, assim como qualquer outra aptidão, ela também é um indicador do avanço da própria humanidade (FISCHER, 2006, p 11). 
Somada a essas novas contribuições teóricas, os documentos tidos como oficiais que orientam e disciplinam os cursos, notadamente as DCNs e os Projetos Pedagógicos dos Cursos (PPCs), possibilitam a promoção de um diálogo entre os fundamentos do letramento, prescritos e almejados nos instrumentos oficiais, com o processo formativo e as práticas de futuros profissionais, especialmente dos professores, uma vez que,

A docência constitui-se numa profissão na medida em que possui um conjunto de conhecimentos próprios para o seu exercício, os quais se diferenciam dos conhecimentos necessários a outras ocupações. Além disso, apresenta como especificidade o fato de ser aprendida continuamente, ao longo da vida e da trajetória profissional [...]. Como consequência, o saber dos professores constitui-se como um saber plural e heterogêneo, uma vez que envolve conhecimentos de diversas naturezas e provenientes de variadas fontes (Tardif, 2012), dentre elas, a prática pedagógica cotidiana da docência (CHAQUIME; MILL, 2016, p. 119).

Essa particularidade formativa do profissional docente, ratificada pelas DCNs para os cursos de formação de professores (Resolução CNE/CP 2, de 01 de julho de 2015), apoia-se numa concepção de formação comprometida com a diversidade cultural e social do contexto em que,

[...] III - o contexto educacional da região onde será desenvolvido; IV - as atividades de socialização e a avaliação de seus impactos nesses contextos; V - a ampliação e o aperfeiçoamento do uso da Língua Portuguesa e da capacidade comunicativa, oral e escrita, como elementos fundamentais da formação dos professores, e da aprendizagem da Língua Brasileira de Sinais (Libras); VI - as questões socioambientais, éticas, estéticas e relativas à diversidade étnicoracial, de gênero, sexual, religiosa, de faixa geracional e sociocultural como princípios de equidade [...] (BRASIL, 2015, p. 5-6).

São algumas das orientações necessárias à consecução das competências formativas oficialmente definidas para os cursos de formação de professores. Entretanto, pondera-se que, apesar da leitura objetiva de tais incisos permitir uma aproximação dos fundamentos e procedimentos oficiais traçados para a formação do professor com a concepção de letramento como prática social situada, já que ancorada numa visão de pensadores e linguistas que compreendem a linguagem como um mecanismo dinâmico, dialógico e sócio-histórico, a letra da lei nem sempre revela as subjetividades que lhe deram materialidade. Por isso, para a compreensão das 
ALVES, D. A.

implicações dessa proposta de letramento, implícita e explícita nos documentos oficiais, de forma associada com a perspectiva de letramento como prática social situada, exigese um debruçar minucioso sobre os diversos pareceres que fomentaram as suas criações.

Dessa forma, dois pareces que amparam as DCNs para os cursos de formação de professores assumem relevância significante ao estudo do letramento com base nas discussões que aqui se apresenta, cujo objetivo geral é promover um diálogo críticoreflexivo entre o letramento, território e ensino formal de geografia. São eles: Parecer CNE/CP $n^{\circ}$ 002/2015 e Parecer CNE/CES n492/2001 (retificado pelo Parecer CNE/CES no 1.363/2001 e consolidado pela Resolução CNE/CES n 14, de 13 de março de 2002).

A seleção de ambos pareceres diz respeito às competências prescritas para o domínio dos conteúdos a serem socializados, de seus significados em diferentes contextos e de sua articulação interdisciplinar definidas pelos conselheiros do CNE sob o $n^{\circ} 02 / 2015$, bem como, às orientações específicas que são ratificadas nos respectivos PPCs, dentre eles, o de Geografia.

Em conformidade com o primeiro parecer, a formação do professor deve abranger o " $[\ldots]$ aperfeiçoamento do uso da língua portuguesa e a capacidade comunicativa, oral e escrita, [...], uso competente das TIC para o aprimoramento da prática pedagógica e a ampliação da formação cultural dos (das) profissionais do magistério e estudantes" (BRASIL, 2015, p. 24-25), além de possuir outros conhecimentos necessários ao desenvolvimento das suas atividades. Apreende-se, desse breve enxerto, a importância que a linguagem e as tecnologias digitais da informação e comunicação (TDICs) oficialmente assumem para a formação docente independente de qual seja a área do conhecimento. Especificamente com relação ao uso das TDICs, é recorrente a advertência das DCNs a respeito de uma formação atenta:

Art. 16 - II - à necessidade de acompanhar a inovação e o desenvolvimento associados ao conhecimento, à ciência e à tecnologia; [...] VI - ao uso competente das Tecnologias de Informação e Comunicação (TIC) para o aprimoramento da prática pedagógica e a ampliação da formação cultural dos(das) profissionais do magistério e estudantes; [...] V - ( à associação) da linguagem dos meios de comunicação à educação, nos processos didáticopedagógicos, demonstrando domínio das tecnologias de informação e comunicação para o desenvolvimento da aprendizagem; [...] VIII (ao) desenvolvimento, execução, acompanhamento e avaliação de projetos educacionais e escolares, incluindo o uso de tecnologias educacionais, diferentes recursos e estratégias didático-pedagógicas; 
ALVES, D. A.

[...] V - (à garantia) aos estudantes do domínio dos conteúdos específicos da área de atuação, fundamentos e metodologias, bem como das tecnologias; [...] VII - (aos) recursos pedagógicos como biblioteca, laboratórios, videoteca, entre outros, além de recursos de tecnologias da informação e da comunicação, com qualidade e quantidade, nas instituições de formação; [...] (BRASIL, 2015, p. 1 a 13).

Ratifica, segundo o parecer dos conselheiros do CNE, que o conhecimento tecnológico deve ser uma preocupação constante referente da Formação de Professores da Educação Básica, em nível superior, curso de licenciatura, de graduação plena.

Ao mesmo tempo, o Parecer CNE/CES n492/2001 que dispõe sobre as DCNs para cursos de Filosofia, História, Geografia, Serviço Social, Comunicação Social, Ciências Sociais, Letras, Biblioteconomia, Arquivologia e Museologia, no que tange ao curso de licenciatura em Geografia expõe que:

\begin{abstract}
A geografia vem evoluindo, nas últimas décadas, tanto pela introdução e aprofundamento de metodologias e tecnologias de representação do espaço (geoprocessamento e sistemas geográficos de informação, cartografia automatizada, sensoriamento remoto etc.) quanto no que concerne ao seu acervo teórico e metodológico em nível de pesquisa básica ( campos novos ou renovados como geoecologia, teoria das redes geográficas, geografia cultural, geografia econômica, geografia política e recursos naturais, etc.), quanto em nível de pesquisa aplicada (planejamento e gestão ambiental, urbana e rural) [...] A atual dinâmica das transformações pelas quais o mundo passa, com as novas tecnologias, com os novos recortes de espaço e tempo, com a predominância do instantâneo e do simultâneo, com as complexas interações entre as esferas do local e do global afetando profundamente o quotidiano das pessoas, exige que a Geografia procure caminhos teóricos e metodológicos capazes de interpretar e explicar esta realidade dinâmica (BRASIL, 2001, p. 10).
\end{abstract}

Da análise associada dos trechos transcritos dos dois pareceres em questão, conclui-se que o domínio da linguagem e do uso das TDICs são imprescindíveis à formação do professor, sendo que, com relação ao professor de Geografia, ciência que tem como papel a leitura e a interpretação do mundo em suas dinâmicas e complexidades espaço-temporais e que, singularmente, se caracteriza por conhecimentos que se fazem pelo uso de tecnologias próprias, tornar-se professor de geografia significa saber ler e interpretar esse mundo em suas mais diversas formas de representação, bem como, dominar as tecnologias necessárias a esse saber. Portanto, as práticas de letramento e o domínio das TDICs são essenciais à formação do professor de 
ALVES, D. A.

Geografia, cuja finalidade reside em habilitá-lo para o exercício na educação básica de forma competente e comprometida com uma visão crítica e inovadora imprescindível para uma sociedade caracterizada por Santos (1998) como "técnico-científicainformacional".

Pelo exposto, apreende-se que a formação do professor precisa estar conexa às novas dinâmicas que interferem nos processos didático-formativos, os quais delinearão o seu perfil enquanto educador. Não há mais espaço para percursos formativos retrógrados, baseados em práticas de letramentos socialmente descontextualizadas e alheias a uma perspectiva de educação fundada num processo dialógico que, na concepção de Freire (1999), “[...] é mais do que transferir conhecimento, é gerar espaços para produzir novos conhecimentos, tanto no âmbito individual como no social" (GOMEZ, 2010, p.12).

Por tanto, a sala de aula como um desses espaços em que se produz os novos conhecimentos constitui-se como “[...] a rede (que) faz e desfaz as prisões do espaço, tornado território: tanto libera como aprisiona. É o porquê de a sala de aula ser o 'instrumento' por excelência do poder” (RAFFESTIN, 1993, p. 204). Poder este que se desvela na "territorialidade humana" do seu espaço objetivo decorrente das relações intersubjetivas inerentes ao processo de ensino e de aprendizagem, as quais são mantidas por seus atores, sujeitos “[...] semiológicos cuja territorialidade é condicionada por linguagens, códigos e sistemas de sinais. O procedimento do homem, de alguma forma, está na constituição linguística do mundo" (RAFFESTIN, 1987, p. 264).

\section{Considerações finais}

Estudos baseados, sobretudo em Street (1984, 2006, 2009 e 2012), que concebem o letramento como uma prática situada vinculada a contextos sociais singulares, à valoração que o sujeito confere às práticas de leitura e escrita e às relações de poder e ideologia, ancoram-se discursivamente nas ideias de pensadores, como Mikhail Bakhtin, o qual, na década de 1990, possibilitou com os estudos da linguística moderna, pensar o letramento como uma forma de interação social, flexível, dinâmica, sócio-histórica e, portanto, muito mais procedimental do que conteudística.

Todavia, ainda na sociedade contemporânea, contemplada com os novos conhecimentos propiciados pelo nascimento da linguística moderna e dos avanços da 
ciência e da tecnologia, logo, caracterizada segundo Corrêa e Jorge como grafocêntrica e tecnológica, o letramento, enquanto prática social situada, não se apresenta como argumento de unanimidade no ambiente acadêmico, uma vez que, na academia não são raros os discursos defensores de concepções que o consideram como técnica padronizada, neutra e passível de ser mecanicamente ensinada à revelia das particularidades dos diferentes saberes.

Tais concepções foram analisadas por Lea e Street (1998) sob duas denominações: modelo de habilidades e modelo da socialização acadêmica. Ambos modelos, apesar de focarem no domínio de habilidades de leitura e escrita próprias e necessárias para o processo de ensino e de aprendizagem dos componentes que integram os currículos dos cursos de graduação, pecam por ignorarem as especificidades contextuais que cada área do conhecimento demanda.

Por outro lado, os novos estudos sobre letramento, que ganharam vozes com o nascimento da linguística moderna, diferenciam-se dos modelos analisados acima por, além de valorizarem a importância do domínio das habilidades de leitura e escrita inerentes ao ambiente acadêmico, evidenciarem os múltiplos letramentos possíveis e necessários na academia, um ambiente culturalmente heterogêneo, cujos cursos e respectivos currículos universitários, também múltiplos em suas modalidades, estruturas e finalidades, requerem gêneros acadêmicos diversos que se constituam como um conjunto de aptidões de leitura e escrita adquiridas num dado contexto, marcadas por relações de poder e ideologia, carregadas de sentidos e significados e, portanto, não homogêneas.

$\mathrm{Na}$ atualidade, conforme os resultados divulgados no ano de 2016 pelo INEP referentes a uma pesquisa etnográfica sobre letramento acadêmico realizada num curso de licenciatura em Geografia, cujo objetivo era a compreensão das práticas de letramento e sua construção por estudantes matriculados no sétimo período curricular, o uso do quadro e giz ainda ocupa papel central no processo de letramento geográfico em detrimento de recursos próprios do ensino da Geografia, a exemplo da leitura de mapas.

A perspectiva de letramento como prática social situada, segundo a qual as práticas de leitura e escrita situam-se no "contexto do poder e da ideologia, e não como uma habilidade neutra, técnica" (STREET, 2009, p. 466), além de ter contribuído, no campo da linguística, para ultrapassar a visão reducionista de letramento como prática mecanicamente conteudística, se aproxima e dialoga geograficamente com a categoria 
território, definida por Raffestin (1993, p. 143-144) como “[...] um espaço onde se projetou um trabalho, seja energia e informação, e que, por consequência, revela relações marcadas pelo poder".

Ainda, o modelo atual de sociedade caracterizada como tecnológica em que ferramentas provenientes da cultura digital ${ }^{4}$ são uma realidade inevitável e, nesse sentido, ampliam as "[...] formas de mediação do conhecimento" (CORRÊA; JORGE, 2016, p. 260), esbarra, segundo Manevy (2009), com um reducionismo da cultura tecnológica à técnica, visto que

\begin{abstract}
Alguns tratam a cultura digital só como uma tecnologia, só como uma técnica, como uma novidade, esse conjunto de transformações da tecnologia que dos anos 70 para cá vem transformando o mundo analógico neste mundo do bit, algo invisível, mágico, que o digital engendra. Agora, se pensarmos como cultura e não só como suporte, acredito que captamos a essência desta transformação, que é a cultura das redes, do compartilhamento, da criação coletiva, da convergência. São processos vivos de articulação, processos políticos, sociais, que impactam nosso modo de vida, de construção e de formulação. E que encontra no digital não um suporte, mas um modo de elaboração. (MANEVY, 2009, p. 36).
\end{abstract}

São muitos os mitos e preconceitos em torno da inserção dos elementos da cultura digital, dentre os quais: a suposta falta de atitude ativo-responsiva dos professores e uma formação automatizada dos alunos devido a separação espaçotemporal entre esses sujeitos no processo de ensino-aprendizagem, o que afasta a dialogicidade tão necessária à formação crítica e reflexiva do aluno. Esses mitos e/ou preconceitos instigam o estudo sobre letramento como prática situada, ou seja, vinculada a um dado contexto que, na contemporaneidade, caracteriza-se pela cultura digital.

Pelo exposto, investigar as práticas de letramento associadas aos aspectos político-pedagógicos específicos do ensino da Geografia, baseando-se, ao mesmo tempo, na defesa de uma perspectiva de letramentos no plural, que não se configura como unânime, revela-se como um desafio de pesquisa, que traz à tona múltiplas inquietações: Como construir práticas de leitura e escrita não homogêneas no ensino formal da ciência geográfica? Como se configura o trabalho com gêneros acadêmicos

\footnotetext{
${ }^{4}$ Lévy (2000) se refere à cultura digital por meio do termo cibercultura e a define como "o conjunto de técnicas (materiais e intelectuais), de práticas, de atitudes, de modos de pensamento e de valores que se desenvolvem juntamente com o crescimento do ciberespaço" (LÉVY, 2000, p.17).
} 
próprios a essa área do conhecimento (globo terrestre, mapas, maquetes, bússolas, fotografias, mostruários ou coleções de rochas, minerais e solos, etc)? Há déficits de leituras e escritas em relação aos recursos próprios ao ensino da Geografia? Qual o papel do professor de Geografia no processo de letramento? Como estabelecer um processo de ensino-aprendizagem efetivamente dialógico e que problematize as práticas de leitura e escrita num ambiente formal de ensino? Com vêm se estabelecendo as práticas de leitura e escrita no ensino formal da geografia diante de um contexto temporal marcado pela cultura digital? No ensino da geografia, as TDICs estão presentes? A falta do prévio letramento digital é um complicador ao letramento no ensino da ciência geográfica?

As respostas as essas questões perpassam, no mínimo, pelo duplo desafio da imprescindibilidade do letramento digital e da compreensão de que o letramento, concebido como prática social situada no contexto de uma sociedade marcada pela cultura digital, em que as TDICs devem ser entendidas como facilitadoras do processo de ensino e de aprendizagem da ciência geográfica de forma crítica e contextualizada, dado que a interação professor-aluno, ao contrário do que se diz, é potencializado por tecnologias de comunicação síncrona (simultânea) e assíncrona (não simultânea), o que torna o ambiente de aprendizagem, seja ele físico ou digital, um verdadeiro território tecnológico.

Assim, mapear, conhecer e compreender a efetividade dessas práticas de letramento, as relações estabelecidas entre os sujeitos envolvidos, os efeitos dos usos sociais da leitura e da escrita nos diversos gêneros acadêmicos, num contexto de cultura digital, cuja ciência aqui analisada, segundo as DCNs definidas pelo CNE, "vem evoluindo, nas últimas décadas, (dentre outros motivos), também pela introdução e aprofundamento de tecnologias de representação do espaço [...]” (BRASIL, 2001, p. 10), são os primeiros passos para a definição de letramento geográfico como prática social situada que não pode estar alheia ao contexto territorial do qual resulta.

\section{Referências}

BAKHTIN, Mikhail. Os gêneros do discurso: problemática e definição. In:

BAKHTIN, Mikhail. Estética da criação verbal. 3a ed. São Paulo: Martins Fontes, 2000. 
BOGDAN, Robert Staszewski; BIKLEN, Sari Knoop. Investigação Qualitativa em Educação - uma introdução à teoria e aos métodos. Porto: Porto Editora, 1994.

BRASIL. Conselho Nacional de Educação. Parecer CNE/CES 492, de 03 de abril de 2001. Diretrizes Curriculares Nacionais dos cursos de Filosofia, História, Geografia, Serviço Social, Comunicação Social, Ciências Sociais, Letras, Biblioteconomia, Arquivologia e Museologia. Disponível em:

http://portal.mec.gov.br/cne/arquivos/pdf/pcr492_01.pdf. Acesso em: 15 jan. 2019.

BRASIL. Conselho Nacional de Educação. Parecer CNE/CP n ${ }^{\circ}$ 002/2015, de 25 jun. 2015. Diretrizes Curriculares Nacionais para a Formação Inicial e Continuada dos Profissionais do Magistério da Educação Básica. Disponível em:

http://pronacampo.mec.gov.br/images/pdf/parecer_cne_cp_2_2015_aprovado_9_junho_ 2015.pdf. Acesso em: 15 jan. 2019.

BRASIL. Conselho Nacional de Educação. Resolução CNE/CP 2, de 01 de julho de 2015. Diretrizes Curriculares Nacionais para a formação inicial em nível superior (cursos de licenciatura, cursos de formação pedagógica para graduados e cursos de segunda licenciatura) e para a formação continuada. Disponível em: http://portal.mec.gov.br/docman/agosto-2017-pdf/70431-res-cne-cp-002-03072015pdf/file. Acesso em: 16 jan. 2019.

CHAQUIME, Luciane Penteado; MILL, Daniel. Dilemas da docência na educação a distância: um estudo sobre o desenvolvimento profissional na perspectiva dos tutores da Rede e-Tec Brasil.Rev. Bras. Estud. Pedagog. 2016.

CLAVALL, Paul. O território na transição da pós-modernidade. Geographia, 1, 1999.

CORRÊA, Hércules Toledo; JORGE, Gláucia Maria dos Santos. A velha questão dos mitos e verdades da $\mathrm{EaD}$ e a relativização das polaridades: a experiência da área da linguagem do CEAD-UFOP. In: EaD: diálogos, compartilhamentos, práticas e saberes / Orgs. Juliana Cordeiro Soares Branco et al. - Belo Horizonte: EdUEMG, 2016.

COSTA, Benhur Pinós da. Microterritorializações urbanas: análise das microapropriações espaciais de agregados sociais de indivíduos same sex oriented em Porto Alegre/RS. In: HEIDRICH, A. L. A emergência da multiterritorialidade: a ressignificação da relação do humano com o espaço. Canoas: Ulbra; Porto Alegre: Editora da UFRGS, 2008.

FISCHER, S. R. História da Leitura. Trad. Claudia Freire. São Paulo: Editora Unesp, 2006.

FREIRE, Paulo. Conscientização. São Paulo: Cortez e Moraes, 1979.

FREIRE, Paulo. Pedagogia da autonomia. Rio de Janeiro: Editora Paz e Terra, 1999.

GOMEZ, Margarita Victoria. Cibercultura, formação e atuação docente em rede: guia para professores. Brasília: Liberlivro, 2010. 
ALVES, D. A.

JORGE, Gláucia Maria dos Santos; CORREA, H. T. A experiência de ensinar leitura e produção de textos nas modalidades presencial e a distância. In: III Encontro Nacional sobre Hipertexto - Interfaces, Belo Horizonte. v. I, 2009.

KRESS, G. Literacy in the new media age. London: Routledge, 2003.

LEA, Mary R.; STREET, Brian. Student writing in higher education: an academic literacies approach. Studies in Higher Education, Dorchester on Thames, v. 23, n. 2, 1998.

LEVY, Pierre. Cibercultura. 2. Ed. São Paulo, Editora 34, 2000.

LOCH, R. E. N. Cartografia: representação, comunicação e visualização de dados espaciais. Florianópolis: Ed. Da UFSC, 2006.

MACEDO, Maria do Socorro Alencar Nunes.; NEVES-JUNIOR, Bernardino. Letramento acadêmico em um curso de Geografia: uma perspectiva etnográfica. Rev. Bras. Estud. Pedagógicos, 2016.

MANEVY, Alfredo. Política da Cultura Digital. In: SAVAZONI, Rodrigo; CONH, Sergio (Org.). Cultura digital.br. Rio de Janeiro: Beco do Azougue, 2009.

MARINHO, M. A escrita nas práticas de letramento acadêmico. Revista Brasileira de Linguística Aplicada, Belo Horizonte, v. 10, n. 2, p. 363-386, 2010.

MOREIRA, Ruy. Pensar e Ser em geografia. São Paulo: Contexto, 2007.

NEVES-JÚNIOR, Bernardino. Práticas de letramento acadêmico em um curso de Geografia. 2012. 128 f. (Mestrado em Educação) - Departamento de Educação, Universidade Federal de São João Del Rei, São João Del Rei, 2012.

RAFFESTIN, Claude. Repères pour une théorie de la territorialité humaine. Cahier/Groupe Réseaux, (7), 1987.

RAFFESTIN. Claude. Por uma geografia do poder. São Paulo: Ática, 1993.

ROJO, R. H. R. Gêneros discursivos do Círculo de Bakthin e multiletramentos. In: Multiletramentos na escola. (Org.). Escola conectada: os multiletramentos e as TICs. São Paulo: Parábola, 2013.

SANTOS, Milton. Técnica, espaço, tempo: globalização e meio técnico-científicoinformacional. São Paulo: Hucitec, 1998.

SOARES, Magda. Alfabetização. In: FRADE, Isabel Cristina Alves Silva; VAL, Maria da Graça Costa. G; BREGUNCI, M. das Graças de Castro. Glossário Ceale de termos de Alfabetização, leitura e escrita par educadores. Belo Horizonte, CEALE/Faculdade de Educação da UFMG. 2014. Disponível em: http://www.ceale.fae.ufmg.br/app/webroot/glossarioceale/verbetes/alfabetização. Acesso em: 18 abr. 2019.

STREET, Brian. Literacy in theory and practice. Cambridge, England: Cambridge University Press, 1984. 


$$
\text { ALVES, D. A. }
$$

STREET, Brian. Perspectivas Interculturais sobre o letramento. Filologia e Lingüística Portuguesa, São Paulo, SP. Humanitas, v. 8, 2006. Disponível em: http://www.fflch.usp.br/dlcv/lport/pdf/sumario08.pdf. Acesso em: 15 jan. 2019.

STREET, Brian. Entrevista Com Brian Street. Tradução: Gilcinei Teodoro Carvalho. Língua Escrita. Belo Horizonte, n.7, 01 Jul. 2009. Entrevista. Disponível em:

http://www.ceale.fae.ufmg.br/pages/view/lingua-escrita-n-7.html. Acesso em: 22 jan. 2019.

STREET, Brian. Eventos de letramento e práticas de letramento: teoria e prática nos Novos Estudos do Letramento. In: MAGALHÂES, I. (Org.) Discursos e práticas de letramento: Pesquisa etnográfica e formação de professores. Campinas: Mercado de Letras, 2012. 